\title{
Research on Financing Innovation of Chinese Small and Medium - sized Technological Enterprises
}

\author{
Liulin Lin ${ }^{1}$, Yun Sun ${ }^{2}$ \\ ${ }^{1}$ Zhuhai City Polytechnic, Zhuhai Guangdong, 519040, China \\ ${ }^{2}$ Beijing Normal University.Zhuhai, Zhuhai Guangdong, 519085, China
}

Key words: Science and technology, Small and medium enterprises, Financing innovation.

\begin{abstract}
China has always been adhering to the "science and technology is the primary productive force", and now science and technology SMEs in promoting China's economic development has an important role. Therefore, for the financing of small and medium-sized enterprises to provide some help to help improve its financing capacity is the focus of national concern. This paper mainly analyzes the financing innovation of China's science and technology small and medium-sized enterprises.
\end{abstract}

\section{Introduction}

For now, 80\% of China's science and technology SMEs are still using bank loans to finance. The main reason for this situation is that most of our small and medium enterprises do not have the standard requirements of our market, that is, do not have the ability to directly finance. At the same time, the regional equity trading center will be limited by the number of investment and geographical, resulting in its low activity, poor mobility, and thus can not meet the needs of corporate finance. Small and medium-sized enterprises in the early stages of entrepreneurship with high risk and high failure rate and other characteristics of the bank appears credit situation, leading to China's science and technology SMEs financing, financing difficulties, the development of small and medium enterprises are facing a huge funding gap. How to innovate the financing mode of science and technology small and medium-sized enterprises in the modern background, to solve the problem of financing and financing, has become the focus of attention of small and medium-sized enterprises.

\section{Definition of small and medium-sized enterprises}

\section{The definition of small and medium - sized enterprises}

Small and medium-sized enterprises are small and medium-sized enterprises, the type of business has a certain scientific and technological characteristics and technology base, science and technology capacity of small and medium-sized enterprises are the driving force for the development of science and technology. The definition of small and medium-sized enterprises in each country will change with the development of the times. However, the basic principles of enterprise division are similar, and the qualitative and quantitative methods are used to define the small and medium-sized enterprises. The qualitative division of small and medium-sized enterprises is mainly based on its economic characteristics, management and operation of the way to make the appropriate judgments, the quantitative division of SMEs is mainly based on its number (the number of operations, total assets and annual income) to carry out determination. At present, China's small and medium enterprises to define the standard: business employees less than 2,000 people, enterprises in the annual income of 100 million. On the basis of this division: enterprise employees in more than 100 
people, the annual income of more than 10 million, defined as medium-sized enterprises; business employees in more than 10 people, annual income of 100 or less, defined as small businesses.

\section{Definition of Small and Medium - sized Technological Enterprises}

Small and medium enterprises to science and technology development as the main driving force for development, generally by the scientific and technological personnel to start the enterprise, the main business research, production and sales of scientific and technological products, its main purpose is to develop its scientific and technological achievements into science and technology Product market, that consumers provide quality technology services and scientific and technological advice. At present, the definition of science and technology enterprises is: talent, technology-intensive, business management with high efficiency, the direction of enterprise development for the development of technology products, with high risk, high market development ability and relatively strong sense of innovation.

\section{Five Stages and Main Features of Small and Medium - sized Technological Enterprises}

Germination stage: science and technology SMEs in the bud, only for a certain technology products have some ideas, but because of environmental reasons and can not produce technology products, technology products can not be successfully transferred to the market circulation of products. Therefore, at this stage the enterprise does not exist in the production and sale of product links, but need to invest a lot of money.

Entrepreneurship stage: Small and medium-sized enterprises in the business period, the results of its scientific and technological research and development has been transformed into market products. In the early stages of the market, the technology products need a lot of promotion, the use of preferential prices in the market to occupy a certain position. Therefore, at this stage, companies need to put a lot of production, and the need for a lot of money to the product to market, no sales revenue. This stage, the enterprise is a complete output stage, and need to invest a lot of money, we can see that this stage belongs to the financing needs of the largest link.

Growth stage: small and medium-sized enterprises in the growth period has the characteristics of rapid growth in this stage of the production process of enterprises more mature and stable, the product has occupied a certain position in the market, the increasing number of customers, enterprises have begun to form Its own marketing features, and also have a fixed product back section.

Maturity stage: Small and medium-sized enterprises in science and technology have matured in the mature period, enterprises will have a stable income, business demand for funds continue to decrease. And if the enterprise to launch new products, its demand for funds will be a big change.

Decline stage: technology SMEs in the recession period, the main push of technology products in the market has been a large number of similar products, resulting in the production of products in the technology is no longer competitive, resulting in a significant gap in the financial aspects of enterprises. Therefore, at this stage, the company will withdraw this product, no longer the product financing.

Key Features:

First, high risk and high returns coexist. Scientific and technological enterprises are mainly scientific and technological achievements into products, will be developed in the technology products to the marketing period, the enterprise will appear more management risks, financial risks and financing risks, this time the enterprise is in a high-risk stage. In order to grow and develop, companies must finance. Science and technology production of small and medium enterprises with public awareness and high technology. In the enterprise to launch new products, there will be no similar products in the market to compete, the production of products will be a monopoly, made high profits.

Second, the high proportion of scientific and technical personnel, high value-added technology products. Small and medium-sized enterprises are mainly to pursue the results of its research to be commercialized and industrialized, so that the production of products to maximize profits. Science and technology SMEs have more high-tech talent to the enterprise's scientific and technological 
achievements into the transformation of scientific and technological achievements in the process, the need for more scientific and technological personnel to the enterprise's products for research and development, production, sales and service, Under normal circumstances, the number of enterprises in science and technology will occupy the total number of enterprises $20 \%$, or even more. According to the specific circumstances of the market to be classified can be found, science and technology enterprises mainly for the biological, aviation, information, new materials and energy and environmental protection industries, the industry compared with the traditional industries, with high added value.

\section{Financing Difficulties of Small and Medium - sized Technological Enterprises}

\section{Financing Difficulties in Germination stage and Entrepreneurship stage}

Small and medium-sized enterprises in the product development and production stage, the technology has its lack of appropriate funds, the lack of loans to do the assets of the loan, no good product sales records. This stage of science and technology SMEs on the demand for funds and banks on the principle of sound business to the contrary. Under normal circumstances, the banks are more fancy corporate profitability and corporate repayment may be the risk, due to the different professional point of view, its technology-based SME technology and future development prospects are not recognized, so science and technology in small and medium enterprises, this stage is more difficult to apply for loans to the bank. In addition, science and technology-based small and medium-sized enterprise technology development funds are mainly government, financial technology to allocate funds, such funds are relatively low interest rates, or even no interest, resulting in small and medium-sized science and technology Capital formation of a greater dependence. However, because the government will consider the country's scientific and technological innovation, national security and long-term development and other large aspects of its financial support for the only strategic products and local science and technology projects. The early stage of development of small and medium-sized enterprises of science and technology is expensive and the financing situation is related to the degree of risk at this stage. The greater the risk, the higher the cost of enterprise financing. At this stage the risk of business is usually the first, the technical risk; second, the enterprise research and development of technology products in the market can be a smooth sales risk. In addition, the enterprise will be with the increase in market demand and the expansion of business scale and other aspects of capital investment and the emergence of financial risk.

\section{Financing Difficulties in Growth stage and Maturity stage}

In the small and medium-sized enterprises into the growth period, its risk in the previous stage has a certain reduction in the enterprise at this stage already have physical assets, the financing difficulties have been reduced. However, enterprises to enhance their competitiveness in the market, or the need to continuously expand the financing channels. In the enterprise into the mature period, the new technology-based small and medium-sized enterprises continue to join, resulting in the production of products produced by the profits are also reduced, companies only continue to product technology transformation, and constantly develop new products to reduce its spending Cost, in the market has a strong competitive edge.

\section{Cloud innovation financing}

\section{The advantages of cloud innovation}

Cloud innovation financing is open and democratic, its scope for the provision of funds is relatively wide. This innovative model will expand the organization to the outside of the organization, so that innovation is not only science and technology $\mathrm{R} \& \mathrm{D}$ personnel and scientific research institutions of the patent, no matter where they are, as long as the technology novel, innovative ideas, novel thinking, 
can join Innovation. Cloud innovation is not like the traditional innovation is generally closed, it is to the global integration of innovative resources configuration, science and technology are small and medium-sized enterprise development backbone funds. Internet finance belongs to the cloud innovation in the financial aspects of the new model, that is, Pratt \& Whitney financial model. In recent years, as people's financial awareness and wealth awareness continue to increase, more and more individuals, institutions to join the lending activities. Internet financing in the P2P network lending and all the two ways, in terms of financing has become a major form of financing. According to China's net loan home to provide the relevant data we can see that in 2013, 99 plus P2P platform, the volume of funds has reached 49 billion. According to the company's research report, in 2009, the global financing of the amount of 530 million US dollars, and in 2011 the amount of financing has reached 1.5 billion US dollars. Under normal circumstances, P2P, co-financing network financing is almost for small and medium enterprises, including financing for the main high-tech enterprises for the high content of science and technology. Therefore, the current funding of small and medium-sized enterprises are mainly entrepreneurial investors, government support funds, venture capital, financial institutions, as well as financial entities or institutions.

\section{Low cost and high efficiency features of Cloud innovation}

Cloud innovation is within the same time through the use of internal and external innovation resources as well as internal and external commercial channels, and low cost of innovative models. It is mainly for the rational use of external resources to save time for research and development of technology products, can effectively reduce the cost of business expenses. In addition, it can also through the Internet and the rational use of information technology to the social resources in their needs to play a certain role, to a certain extent, to reduce the time spent on innovation to accelerate innovation Dissemination, enhance the efficiency of scientific and technological product development. Through the Internet, the major search engines, mobile terminals and other large data tools, the Internet financial model has become a large difference with the commercial banks of indirect financing, and capital markets in the third financing model there is a big difference, From the perspective of cloud innovation, the nature of the Internet financial model is the same as the direct financing model, which can effectively reduce the cost of the transaction. In addition, in the case of more individuals, institutional funding providers join and compete with each other, science and technology SMEs have more financing options, can reduce the cost of financing. Small and medium-sized enterprises can be based on their own actual situation to the cost of the corresponding integration of funds to achieve low-cost, efficient financing.

\section{Cloud innovation group wisdom advantage}

Talent belongs to the basic conditions for enterprises to achieve innovation and the basis for ensuring the healthy growth of enterprises. In particular, high-tech enterprises are mainly based on the technical ability of talent, create the ability, innovative thinking and innovative results to transform into their own characteristics of innovative enterprises, only talent for enterprises to create invisible wealth. Cloud innovation is a model of global innovation through a third-party platform that attracts more innovative people to develop innovative solutions that enable more communication and communication between people and, to a certain extent, To achieve group wisdom, which can make up for the lack of innovative talents of science and technology SMEs.

\section{High technology and low consumption advantage of Cloud innovation}

Cloud innovation is through the Internet to modern information technology and cloud computing integration, to achieve high-tech features. At the same time, cloud innovation is more focused on how to produce a small eco-environmental marketing, resource utilization of high technology products. Clouds in the operating system and application resources sharing and virtualization, can effectively improve the utilization of the server, which can achieve the cost of innovation, energy saving purposes, and can also promote the platform of civilization and green economy. 


\section{Conclusion}

It can be seen that the difficulties of financing small and medium-sized enterprises in financing will change with the change of people's financial management consciousness. Now, the financing choice of enterprises will increase gradually. Enterprises can choose suitable financing methods according to their actual situation to achieve low Cost, high yield, enhance the competitiveness of enterprises in the market.

\section{Acknowledgement}

Project: One of Humanities and Social Sciences key issues of Zhuhai City Vocational and Technical College, the title of "science and technology financial development of science and technology enterprises in small and medium-sized enterprises technological innovation impact mechanism Zhuhai City as an example" Project ID: 20151202.

\section{References}

[1] Ma Zhongmin. Research on the Construction of Innovation Mode of Small and Medium-sized Technological Enterprises - "Internet +", Science and Technology Innovation and Application, 2016, (24): 270-271.

[2] Huang Jia. Small and medium-sized enterprise financing obstacles and countermeasures, China Business Theory, 2016, (10): 72-74.

[3] Shen Bo. Jiangsu Province, innovative small and medium-sized enterprise financing constraints empirical study, China Business Theory, 2016, (32): 38-39.

[4] Peng Xiao. Pushing the countermeasures of promoting private capital to alleviate the financing difficulties of technological innovation of small and medium-sized enterprises, Inner Mongolia Coal Economy, 2016, (10): 14-15.

[5] Kang Xi. Science and technology of small and medium-sized enterprise capital structure of the empirical study, China Business Theory, 2016, (02): 40-42.

[6] Wang Xiaoping. Science and technology of small and medium enterprises financing path evolution and reconstruction, Friends of Accounting, 2015, (11): 89-94.

[7] Yang Zheng, Lu Lin. Research on financing mode of small and medium - sized enterprises based on China 's national conditions, Journal of Shanxi Economic Management Cadre College, 2015,23 (03): 49-52.

[8] Fu Xiaojun.Comparison of Financing Structure of Small and Medium-sized Enterprises in China and America, Jiang Shang Shang, 2015, (01): 76-77. 